\title{
A tristeza como subjetividade da ausência no romance "A Porquinha de rabo esticadinho", de Rubem Alves
}

\section{The sadness as a subjectivity of the absence in the romance "The little pig with taut tail", by Rubem Alves}

\author{
Terezinha Richartz ${ }^{*}$ \\ (D) https://orcid.org/0000-0002-8872-1210
}

Recebido em: 13/07/2018

Aceito para publicação em: 16/11/2018

RESUMO: A discussão sobre a inclusão social do deficiente ganha espaço graças à legislação que garante acesso e respeito ao diferente. Como um artefato cultural importante, a literatura também apresenta enredos que incluem personagens deficientes, contribuindo para o debate sobre a importância e as dificuldades da inclusão. Assim, o objetivo deste artigo é discutir a dificuldade da personagem Lili, no romance "A porquinha de rabo esticadinho", de Rubem Alves, de aceitar a diferença para valorizar sua singularidade, construindo, dessa forma, uma nova subjetividade.

Palavras-chave: Deficiência. Literatura. Subjetividade da ausência

ABSTRACT: The discussion about the social inclusion of the disabled gains space thanks to the legislation that guarantees access and respect to the different. As an important cultural artifact, literature also presents plots that include disabled characters, contributing to the debate about the importance and difficulties of inclusion. Thus, the objective of this article is to discuss the difficulty of the character Lili, in Rubem Alves' novel "The little pig with taut tail", to accept the difference to value its singularity, thus constructing a new subjectivity.

Keywords: Disability. Literature. Subjectivity of absence

\section{Introdução}

Na sociedade paradoxal em que se vive atualmente, em algumas situações, os sujeitos querem ser diferentes; em outras, querem ser iguais. Ao mesmo tempo em que não se deseja ser igual aos outros na vestimenta usada numa ocasião especial e nas habilidades no mercado de trabalho, que valoriza a criatividade e a

\footnotetext{
* Doutora em Ciências Sociais pela Pontifícia Universidade Católica de São Paulo (2007). Professora do Mestrado em Letras e professora do EAD da Universidade Vale do Rio Verde. E-mail: terezinha@unincor.edu.br.
} 
singularidade, discrimina-se quem tem aparência diferente, especialmente quem é deficiente.

A literatura, por sua vez, é um produto cultural que está presente no contexto social e pedagógico das crianças, permitindo que se sintam representadas, proporcionando identificação através das histórias. Além disso, é um artefato capaz de comunicar às crianças o que é adequado ou não, influenciando de forma implícita e, por vezes, mesmo explicitamente seus comportamentos, discursos e ideologias, os quais, em geral, prevalecem até a vida adulta.

Como pesquisadora preocupada com a influência da literatura no comportamento social dos leitores, visualizei na obra "A porquinha de rabo esticadinho" a possibilidade de apresentar ao leitor as angústias e a luta diária dos deficientes em busca da aceitação da sua condição até conseguir assumir a diferença e prosseguir sua vida.

O romance também possibilita que o leitor conheça a angústia de quem nasceu com uma falta. Os conflitos internos vivenciados e, muitas vezes, não exteriorizados pelos deficientes e seus familiares podem ser acompanhados por meio do enredo literário, assim, sensibilizando o leitor sobre as agruras da experiência da ausência.

Os diversos agentes sociais envolvidos na trama se posicionam em relação aos deficientes de acordo com dois modelos discursivos já sedimentados historicamente: o modelo médico e o modelo social. É a partir dessa perspectiva que o romance é analisado.

\section{Da percepção da discriminação para a subjetividade da ausência}

A literatura infantojuvenil é concebida como um artefato cultural porque orienta e transmite diversas formas de conhecimento que são vitais na formação da identidade e da subjetividade dos sujeitos.

Ao trazer para seus enredos a temática da inclusão social apresentando personagens com deficiência, a literatura possibilita a reconstrução de discursos sobre o ser e o estar desses sujeitos na sociedade. Como o discurso é construído a partir de fatores sociais e históricos, é provisório e mutável.

Segundo Foucault (1997, p. 136), o conceito de prática discursiva se refere a um "conjunto de regras anônimas, históricas, sempre determinadas no tempo e no espaço, que definiram, em uma dada época e para uma determinada área social, econômica, geográfica ou linguística, as condições de exercício da função enunciativa". O discurso é prática, é ação. A linguagem não apenas nomeia o mundo, mas o constrói (FOUCAULT, 2004).

No que se refere à questão da deficiência, historicamente, há dois modelos discursivos que construíram o tema: o modelo médico e o modelo social (RICHARTZ, 2017).

O discurso do modelo médico atribuiu ao indivíduo que tem o corpo deficiente a dificuldade de inserção social. Como o corpo doente é limitado, os laudos médicos atestam a extensão da deficiência e classificam o corpo.

No modelo social, a questão da deficiência deixa de ser priorizada no indivíduo e é vinculada à sociedade, uma vez que as desvantagens enfrentadas 
pelos indivíduos deficientes são decorrentes de uma sociedade que tem problemas na sua estrutura social, com vias e prédios não acessíveis e projetos pedagógicos escolares não adaptados. Assim como no modelo médico, no modelo social, o deficiente não é ouvido. As decisões são pensadas por quem é "normal" na tentativa de ajudar e de melhorar as condições dos deficientes.

Portanto, esses dois modelos não desenvolvem a emancipação dos deficientes e quem de fato vivencia as dificuldades da diferença ou é tratado como culpado ou como vítima da deficiência, pois a sociedade apresenta barreiras na maioria dos casos intransponíveis para a inclusão. Portanto, é necessário criar uma nova modalidade de abordagem da questão. No presente artigo, defende-se que é preciso construir um modelo que seja estabelecido a partir da subjetividade de quem é deficiente. Nesse modelo, os deficientes se constituem como sujeitos no espaço social, criando-se uma nova subjetividade: a subjetividade da ausência (RICHARTZ, 2017).

Retomando-se o pensamento de Foucault, ressalta-se que o filósofo é contrário à tese de que é possível a afirmação da emancipação em soluções universais, baseando-se em um conceito de corpo desprovido do seu processo histórico-social. Para Foucault, a constituição da identidade do sujeito se dá através do corpo.

As diferenças marcantes nos corpos, em especial dos deficientes, sempre chamaram a atenção das pessoas em diversas sociedades (FOUCAULT, 2001). Na Idade Média, o hospital era usado como espaço para segregar. Pobres, doentes e loucos eram internados para que não tivessem contato com os outros indivíduos, pois eram considerados perigosos, além disso, havia a possibilidade do contágio de algumas doenças (FOUCAULT, 1979, p. 88-89).

$\mathrm{Na}$ "História da Sexualidade I", Foucault (1988) aborda o controle feito ao corpo, especialmente em relação às restrições religiosas e morais apregoadas pela igreja, que produzia um discurso calcado na noção de pecado. De acordo com o autor, o corpo é o lugar onde são apoiadas as práticas discursivas e não discursivas. Por isso, o corpo é maleável, formatado historicamente e está em constante metamorfose.

No que se refere ao discurso da literatura infantojuvenil, há histórias denunciadoras, mas também enredos que eternizam os preconceitos, os estereótipos ou os estigmas. Na tese de doutorado "Espelho convexo: o corpo desviante no imaginário coletivo pela voz da literatura infantojuvenil", Amaral afirma que:

[...] a literatura está repleta de armadilhas traiçoeiras enredando o deficiente, o diferente, em malhas maniqueístas de bondade e maldade, virtude e pecado, santidade e malícia, feiura e beleza... Ou o mutilado é bom, sábio, virtuoso, heroico - e com isso neutraliza-se, compensa-se a deficiência -; ou é cruel, malicioso, covarde, objeto - e com isso estigmatiza-se a diferença. $\mathrm{O}$ folclore também não é imune a esse viés, exemplos disso são os gênios silvestres: Saci-Pererê e Curupira - maliciosos, hostis, porta-vozes de desgraças e enredamentos - mutilados ambos (AMARAL, 1992, p. 33). 
Dessa forma, com personagens altamente estigmatizados, as obras literárias reforçam os estereótipos sobre os deficientes e, em vez de valorizar a pessoa, criam adjetivos que apontam para os extremos pejorativos.

Para Foucault (2012), na pós-modernidade, através de um movimento paradoxal, o sujeito é, ao mesmo tempo, constituído e constituidor de sua subjetividade. Essa se dá através dos discursos permeados por relações de poder, implantados por uma rede complexa de narrativas e práticas incertas. Tanto o sujeito quanto a subjetividade são descentrados e fragmentados. Nesse sentido, a emancipação - também chamada por Foucault de práticas de liberdade - acontece nas particularidades, não em lutas universais. No caso dos deficientes, a subjetividade da ausência aponta para uma questão específica, vivenciada por eles, sendo necessário levar em conta o contexto histórico, cultural, social e político em que cada deficiente está inserido.

Foucault afirma que o dispositivo da sexualidade - tão bem explicitado nas obras "História da Sexualidade I" (1988), "História da Sexualidade II" (1984), e "História da Sexualidade III" (1985) - procura controlar os corpos, mas todo controle gera resistência, levando ao aparecimento de novas subjetividades. Assim também o corpo deficiente, tolhido historicamente, tem potencial transformador.

Desse modo, o corpo é a origem da subjetividade da ausência, de onde pode brotar a emancipação. Como os dispositivos disciplinares, especialmente a família, a escola e o hospital, que "esconderam" o deficiente, foram construídos historicamente, é na história que novas práticas de subjetivação são concebidas. Uma vez que a subjetividade não é fixa, ela tem potencial transformador, produzindo novas formas de o deficiente se relacionar com o mundo a partir da noção de ausência.

O conceito de subjetividade aparece de maneira mais incisiva nas obras “História da Sexualidade II" (1984) e “História da Sexualidade III" (1985). Foucault defende que, como o sujeito é corpo, a subjetividade está relacionada com um corpo concreto; no presente caso, um corpo ou uma mente deficiente, por isso é um modo de vida que estabelece relação de forma criativa ou não com as coisas, diferentemente de um corpo sadio. O elo entre subjetividade e corpo só pode ser pensado em relação ao tempo, pois não é fixo. A subjetividade é estabelecida a partir de como um corpo jovem, velho, normal ou deficiente se relaciona com os fatos durante a vida.

Pode-se referir aqui as restrições de inserção no mercado de trabalho e as dificuldades com a falta de acessibilidade dos deficientes, que são impossibilitados de entrar em vários lugares, de participar efetivamente de muitas situações quando comparados a um corpo sadio de um jovem em plena forma física.

A deficiência é algo inerente ao corpo, à condição física ou intelectual da pessoa. Destarte, o termo mais correto a ser usado é o de ausência. Porque ausência na subjetividade é uma condição. Não adianta colocar uma prótese mecânica na mão; ela pode ajudar o indivíduo a fazer as coisas, mas o sujeito não deixa a condição de deficiente (RICHARTZ, 2017).

Outra questão importante apresentada por Amaral (1992) é que, na literatura infantojuvenil, são poucas as personagens humanas relacionadas à deficiência. 
Mas por que, então, representar a deficiência através de animais? Os animais fazem parte da rotina das pessoas. Os animais de estimação estão dentro de casa. Dessa forma, ao tratar da deficiência nos animais, atinge-se o objetivo de evidenciar as dificuldades dos deficientes no dia a dia.

Rubem Alves escolheu um animal para falar das diferenças no romance "A porquinha de rabo esticadinho". Na obra, o autor apresenta uma manada de porcos cujos integrantes nasceram todos iguais, exceto Lili. Em vez de ter o rabo enrolado, o rabo de Lili é esticado. Mas essa diferença não foi percebida pelos porquinhos na ocasião do seu nascimento, uma vez que a percepção da diferença é dada pelo outro.

Iguaizinhos. Bem, nem todos. O burro, discreto observador, notou que na fileira de rabinhos enrolados como mola havia um esticado como um prego. Os porquinhos, é claro, não se davam conta disso. Eram só boca; só lhes interessava mamar. Além do que seus olhinhos ainda estavam fechados. Não podiam nem comparar e nem perceber as diferenças. Eram todos felizes (ALVES, 2001, p. 9).

Mas o tempo passou. Os olhinhos se abriram. E aconteceu que, certo dia, um deles se deu conta daquilo que o burro percebera.

- Vejam só - disse ele espantado -, Lili é diferente. Nós temos rabos enroladinhos. Ela tem rabo esticadinho (ALVES, 2001, p. 9).

No livro "As palavras e as coisas", ao analisar o quadro de Velázquez "As meninas", Foucault (1995) aponta a importância do olhar do outro como parâmetro para ver nosso próprio corpo. O padrão de normalidade é estabelecido socialmente. Então, o deficiente se espelha no outro considerado "normal" e vê que falta alguma coisa no seu corpo.

Como a identidade depende de outra identidade para existir, pois ela é uma construção social, através do olhar perplexo dos seus irmãos, Lili tomou consciência da sua diferença. Uma vez que essa diferença é relacional, é usada para excluir, afinal, o rabo enrolado é considerado parte constitutiva da manada. "Se os rabos enrolados são melhores que os esticados, isso é assunto que ninguém discutiu. A única coisa que importava era que havia oito iguais e um diferente. E, de repente, havia oito pares de olhos olhando o rabinho de Lili" (ALVES, 2001, p. 9).

A identidade serve para balizar a forma como o sujeito se localiza em uma estrutura social, sendo usada também para situar o sujeito socialmente. Em outras palavras, pode ser empregada tanto para incluir como para excluir o sujeito do grupo social. A porquinha se sentiu excluída. "Quem não pertence ao bando dos iguais fica fora. E quem fica fora tem vergonha. Se esconde. Lili ficou assim. Não queria mais brincar. Ficava sozinha, em casa, assentada sobre o rabinho, pensando no rabinho, com raiva do rabinho" (ALVES, 2001, p. 10).

É comum a deficiência gerar sofrimento e isolamento. Alguns deficientes permanecem dentro de casa e os que tentam participar ativamente da sociedade encontram ruas, prédios e pessoas não acessíveis. Por isso, tentar ser como o 
"normal", esconder ou negar a deficiência é comum na tentativa do sujeito de ser aceito. Com Lili foi assim. Ela lutou muito para mudar. Pediu até ajuda dos céus. “- Papai do céu, me dá um rabinho enroladinho... Mas parece que papai do céu pertencia ao time dos oito, porque nada fazia para ajudar Lili" (ALVES, 2001, p. 10).

O sofrimento dos deficientes reside no olhar preconceituoso e de desprezo de quem se considera "normal". A padronização não é questionada. O fato de a maioria nascer com determinadas características não significa que se trata da única forma de ser.

No romance de Rubem Alves, na figura da mãe, a família entra em cena para tentar amenizar o sofrimento de Lili. Primeiramente, tentou-se fazer a porquinha aceitar a diferença. Mas como a empreitada foi malsucedida, foram colocadas em prática outras alternativas. A família mudou os hábitos alimentares, oferecendo a Lili comida enrolada, como broto de samambaia, na tentativa de enrolar o rabo da porquinha; fez simpatias que prometiam enrolar o rabo; buscou ajuda na ciência e, dessa forma, o cabeleireiro fez um procedimento para enrolar o rabinho de Lili, no entanto, a solução se desfez assim que o rabinho foi lavado (ALVES, 2001).

No enredo da obra de Rubem Alves, a mãe porca, depois de todas as tentativas frustradas, não desanimou e procurou a Arara, que filosofou o que a maioria dos que não têm corpo deficiente acredita.

O que importa - ela dizia - são os pensamentos positivos. Os pensamentos positivos têm força. Portanto - concluiu - se Lili tiver força de vontade [grifo nosso] (isto é muito importante!) e diariamente só pensar no seu rabo enrolado, ele acabará por obedecer aquilo que a cabeça manda (ALVES, 2001, p. 15, grifo nosso).

$\mathrm{Na}$ tentativa de mudar o corpo da porquinha para torná-la igual aos seus irmãos, muitas ações foram realizadas sem sucesso. $O$ que chama a atenção no enredo é que, quando as alternativas buscadas fracassam, especialmente as do modelo médico, através dos tratamentos aos quais a protagonista foi submetida, a culpa é dirigida ao deficiente, que não tem força de vontade. Culpabilizar o diferente é uma forma de não aceitar que a sociedade é preconceituosa, que estigmatiza e rejeita, de não aceitar a pessoa como ela é.

O modelo médico é usado na tentativa de "curar" a porquinha. Mas somente quando aceita sua condição, entendendo que aquela diferença faz parte do seu corpo, Lili começa a olhar para frente.

A inserção do deficiente no mercado de trabalho também é um processo complicado. Conquanto, no modelo social, as políticas inclusivas tenham melhorado significativamente, muitos espaços são acessíveis, porém, a mobilidade ainda é reduzida, fazendo com que o deficiente, muitas vezes, não se sinta capaz de trabalhar.

Foi o que aconteceu no primeiro momento com a porquinha Lili. Chegou à cidade um circo que anunciou: “- Respeitável público! Nosso circo está à procura de dois jovens que desejem se tornar artistas e estejam prontos a correr o mundo para fazer as pessoas felizes. Amanhã, bem de manhã, entrevistarei os candidatos 
desta fazenda, se houver..." (ALVES, 2001, p. 18). Muitos candidatos se apresentaram para a vaga. Foi fácil escolher o porquinho para ser palhaço. “É este o primeiro escolhido. Perfeito para um palhacinho. Este rabinho enrolado fará todos darem risadas" (ALVES, 2001, p. 19).

O palhaço apresenta características menos específicas e a maioria dos sujeitos pode trabalhar como um palhaço. Ele é caricaturado: pés grandes, roupa extravagante, nariz pintado. Pode até ter um rosto triste por trás da máscara, mas o que aparece é a caricatura de alguém alegre. Depende-se muito mais dos enfeites para deixá-lo chamativo do que da habilidade individual. O corpo fica escondido pela maquiagem. Ninguém cobra perfeição nos movimentos. Quanto mais desengonçado for, mais o público vai se divertir.

No entanto, o circo não queria só um palhaço. Procurava outro artista para ser trapezista e, nessa função, as características eram outras, como mostrava a especificação.

Os trapezistas vivem sob o perigo, sabem que a vida não é palhaçada engraçada, nem tudo é riso. Nunca olham para o próprio rabo, atrás, mas sempre para frente. Quem olha para trás cai sobre o abismo e morre... Eles têm um rosto diferente, um sorriso que não é risada, misturada com um pouquinho de tristeza. E é por isso que os outros os amam de um jeito diferente: eles riem do palhaço, mas voam com o trapezista. Um trapezista a gente conhece pelo jeito de olhar... (ALVES, 2001, p. 20).

O trapezista não pode errar. Precisa estar concentrado para não cair. Depende da perfeição do movimento para fazer uma boa apresentação e, ao mesmo tempo, não se machucar.

O dono do circo olhava ao redor, procurando. E seus olhos se encontraram com os de Lili.

- Menina, venha cá. Que é que você tem nos olhos? Parecem olhos de trapezista. Você não gostaria?

- Mas... o meu rabinho - ela disse quase pedindo desculpas.

- Quem se interessa por isso? Quem tem rabo enroladinho passa o tempo todo olhando ou para trás ou para o espelho. Mas quem não tem olha para frente, para cima, para o vazio. E é isso que torna belas as pessoas: não o que elas têm sobre a pele, mas o que têm dentro dos olhos... Lili sorriu e disse que sim. Transformou-se na trapezista de olhos tristes, que todos amavam. E nunca mais se preocupou com o seu rabinho (ALVES, 2001, p. 21).

Lili vivia na marginalidade, se desculpando, pedindo perdão por sua condição. Como deficiente não entendia ser capaz de trabalhar no circo. Esse comportamento é condizente com a lógica real de representação social dos deficientes: a maioria é considerada incapaz e, por isso, fica em casa dependendo de programas sociais. 
Ao chamar Lili para integrar o espetáculo, o dono do circo abriu a possibilidade de a porquinha se reinventar. Em cima da corda, Lili prendia a atenção das pessoas com as marcas da tristeza expressa no seu olhar. O deficiente não pode negar as marcas da deficiência. Elas fazem parte do corpo. São constitutivas da sua subjetividade. Quando os artefatos artísticos e literários incorporam o deficiente, essa ação serve como vitrine para outros deficientes sentirem que também podem atuar.

A metáfora do olhar triste aponta para a incompletude da porquinha. Lili toma consciência de que é deficiente e aceita sua condição construindo um caminho que é só seu. Integrar o trapézio sugere o nascimento de uma nova identidade: a subjetividade da ausência. Lá não há enfeites, nem artimanhas. A precisão nos movimentos é imprescindível.

Para Hall, não existe uma identidade fixa e coerente, mas são possíveis diversas identidades com as quais o sujeito se identifica, ainda que temporariamente no decorrer da vida. De acordo com o autor, as identidades "não são coisas com as quais nós nascemos, mas são formadas e transformadas no interior da representação" (HALL, 2006, p. 48).

Dessa forma, a porquinha não tem uma identidade fixa por toda a vida. Apesar do referencial estável construído e perpetuado por relações sociais excludentes e estigmatizadas, as quais colocam em pauta diversos processos sociais que marginalizam o deficiente, como aconteceu com Lili quando sentiu o peso do olhar dos irmãos e do burro, Stuart Hall afirma:

O sujeito previamente vivido como tendo uma identidade unificada e estável, está se tornando fragmentado; composto não de uma única, mas de várias identidades, algumas vezes contraditórias ou não resolvidas. Correspondentemente, as identidades, que compunham as paisagens sociais 'lá fora' e que asseguravam nossa conformidade subjetiva com as 'necessidades' objetivas da cultura, estão entrando em colapso, como resultado de mudanças estruturais e institucionais. O próprio processo de identificação, através do qual nos projetamos em nossas identidades culturais, tornou-se mais provisório, variável e problemático (HALL, 2006, p. 12).

Destarte, nesse cenário paradoxal em que o deficiente é ora tratado como coitado, ora como culpado, criar novas identidades em que a ausência possa ser incorporada como parte da vida e a diferença possa ser valorizada passa a ser vital para que o deficiente seja verdadeiramente respeitado e valorizado.

O olhar triste é uma metáfora que remete à tomada de consciência acerca da deficiência. Quando Lili compreendeu que era diferente, ficou triste. Assumir essa condição é preponderante para o deficiente construir sua subjetividade. Precisa encontrar um caminho que seja seu, deixando de lado o modelo médico e o modelo social que o tratam como desventurado. É necessário parar de esperar a cura que é impossível em muitos casos ou as soluções prontas que vêm de fora, como se esses 
modelos fossem capazes de eliminar os problemas dos deficientes. Afinal, os dois modelos tentam "resolver" a vida e as dificuldades dos deficientes sem escutá-los.

Quando o deficiente assume que a deficiência é constitutiva do seu corpo, surgem novas possibilidades. O rabinho de Lili não ficou mais em evidência no trapézio, todavia, a tristeza, já internalizada pela vida sofrida, era o sentimento que o público apreciava. Nesse sentido, de acordo com Amaral (1992), o olhar do outro tem a capacidade de marcar quem possui uma diferença e os personagens diferentes/deficientes são construídos, normalmente, a partir de três vertentes: vítima, herói e vilão. Na primeira, o personagem apresenta sentimentos como tristeza, desgosto, solidão, conformismo, desamparo e desesperança; o herói possui alta competência intelectual, extrema sensibilidade, coragem exacerbada e talentos especiais; por fim, a imagem do vilão traduz atitudes e ações condenáveis, tais como intolerância e agressividade.

Lili saiu da condição de vítima, que vivia isolada, e passou à condição de heroína, sendo aplaudida pela perfeição dos seus movimentos no picadeiro.

A maior parte dos discursos, quer sejam legais ou sociais, tenciona suprir a falta que as vítimas da deficiência sentem. A acessibilidade tão difundida hoje visa suprimir a falta, mas a carência não é possível repor. Quando falta um braço, é possível implantar um braço mecânico; se faltam pernas, existem pernas mecânicas ou cadeira de rodas que ajudam o deficiente nos deslocamentos. No entanto, esses paliativos não tiram do sujeito a condição de deficiente.

A ausência como condição pressupõe uma leitura de mundo a partir do deficiente. O desafio é uma prática discursiva que nasça da subjetividade de quem é deficiente, ou seja, da subjetividade da ausência. Os laudos médicos continuam sendo usados como parâmetro científico para legitimar os direitos dos cidadãos. A legislação é cada vez mais inclusiva, no entanto, a emancipação só acontece de fato quando a subjetividade de quem é deficiente aparece, pois a subjetividade da ausência só pode ser pensada por quem vive essa condição.

Foucault não acredita que é possível uma forma geral de emancipação que resulte em soluções universais. Assim, as práticas de liberdade do deficiente se dão a partir da orientação legal, mas a emancipação se dá nas lutas individuais. $\mathrm{O}$ micropoder constituído nas práticas cotidianas do deficiente faz com que a inserção no sistema social possa efetivamente acontecer.

\section{Conclusão}

Rubem Alves traz para a narrativa da literatura infantojuvenil as agruras de uma personagem que nasceu diferente. Através do seu romance, é possível acompanhar as dificuldades vivenciadas pela personagem Lili ao perceber que era diferente, enfrentando preconceitos da família, dos vizinhos e das pessoas que conviviam com ela.

Em razão dos construtos que foram impostos a Lili, ela rejeitou seu corpo e procurou modificá-lo através do que tinha de melhor à sua volta. Mas foi a partir da tomada de consciência da sua condição que a porquinha mudou sua vida. Seu 
rabo não era enrolado e ela precisou se reinventar. Como a identidade é um sistema de representação, a porca passou a se identificar como deficiente.

Tendo em vista que a identidade é cambiante, essa foi sendo construída e modificada de acordo com as experiências da porquinha. Aos poucos, Lili aceitou que era deficiente. Em vez de olhar para o que faltava em seu corpo, passou a valorizar o que era possível fazer com a ausência nele constituída. Dessa forma, Lili se tornou uma deficiente trapezista de sucesso.

Considerando-se que a subjetividade é fragmentada, a emancipação nessa categoria é individual, pois cada deficiente precisa encontrar seu jeito de ser e de estar no mundo, levando em conta sua deficiência. Mesmo sabendo que a maioria dos deficientes ainda não consegue ser incorporada na vida social e no mercado trabalho, no romance de Rubem Alves, Lili assume seu corpo diferente e se integra ao trabalho.

Nesse sentido, o olhar triste de Lili, que faz parte da constituição do sujeito, remete à subjetividade da ausência e não à igualdade. A partir da subjetividade da ausência, Lili se relaciona com o mundo tendo em conta a noção de ausência.

Compreende-se que a acessibilidade é um direito. Assim, o que se propõe não é que o deficiente seja como o sujeito "normal", mas que seja respeitado, valorizado e incorporado à literatura, ao mercado de trabalho e à vida social por sua singularidade. $\mathrm{O}$ direito de ser diferente se sobrepõe ao direito à igualdade, uma vez que aponta para a diversidade tão cara atualmente. Como afirma Boaventura de Souza Santos (2006, p. 316), "temos o direito a ser iguais sempre que a diferença nos inferioriza; temos o direito a ser diferentes sempre que a igualdade nos descaracteriza".

\section{Referências}

ALVES, Rubem. A porquinha de rabinho esticadinho. 9. ed. São Paulo: Loyola, 2001. AMARAL, L. A. Espelho convexo: o corpo desviante no imaginário coletivo pela voz da Literatura Infanto-Juvenil. 1992. 441f. Tese (Doutorado em Psicologia Social) Universidade de São Paulo, São Paulo, 1992.

FOUCAULT, Michel. Microfísica do poder. Organização e tradução de Roberto Machado. Rio de Janeiro: Edições Graal, 1979.

. História da sexualidade 1: a vontade de saber. Rio de Janeiro: Graal,1988. . História da sexualidade 2 : o uso dos prazeres. Tradução de Maria Thereza da

Costa Albuquerque. $8^{\text {a }}$ ed. Rio de Janeiro: Graal, 1984.

. História da sexualidade 3: o cuidado de si. Tradução de Maria Thereza da

Costa Albuquerque. $8^{\text {a }}$ ed. Rio de Janeiro: Graal, 1985.

. As palavras e as coisas. São Paulo: Ed. Martins Fontes, 1995.

- Arqueologia do saber. Trad. L. F. Baeta Neves. Rio de Janeiro: Forense

Universitária, 1997.

. Os anormais. São Paulo: Martins Fontes, 2001.

. Vigiar e punir. Petrópolis: Vozes, 2004. 
Ética, sexualidade, política. $3^{\text {a }}$ ed. Rio de Janeiro: Forense Universitária, 2012. (Coleção Ditos \& Escritos).

HALL, Stuart. A identidade cultural na pós-modernidade. Tradução Tomas Tadeu da Silva e Guaracira Lopes Louro. 11 ${ }^{\mathrm{a}}$ ed. Rio de Janeiro: DP\&A, 2006.

RICHARTZ, Terezinha. O discurso da deficiência como "subjetividade da ausência". Ética, política, religião. AZEVEDO, Marco Antonio et al (Org.). Ética, política, religião. São Paulo: ANPOF, 2017b. 552 p. - (Coleção XVII Encontro ANPOF). P. 109-120. ISBN 978-85-88072-47-3. Disponível em: <http://www.anpof.org/portal/images/eticapoliticaereligiao2-5-2018.pdf>. Acesso em: 14 maio 2018.

SANTOS, Boaventura de Souza. A construção intercultural da igualdade e da diferença. In: SANTOS, Boaventura de Souza. A gramática do tempo. São Paulo: Cortez, 2006. p. 279-316. 